\title{
Escape latencies at three levels of electric shock in rats with amygdaloid lesions'
}

\author{
ERNEST D. KEMBLE and GARY J. BECKMAN, University \\ of Minnesota, Morris, Minn. 56267
}

Amygdalectomized Ss escaped more rapidly than control Ss at three US intensities. This seemed to result from a greater reluctance of control Ss to enter a compartment where they were previously shocked. The responses of amygdalectomized Ss, once established, were also very insensitive to changes in US intensity.

Attempts to demonstrate active avoidance deficits in rats with amygdaloid lesions have yielded inconsistent results (Dicara, 1966; Kemble \& Tapp, 1968; Robinson, 1963; McNew \& Thompson, 1966). Recently, Bagshaw \& Pribram (1968) showed that amygdalectomized monkeys had a lowered threshold for electric shock (as measured by the GSR) and failed to respond differentially to various US levels. The present experiments were designed to determine whether rats with extensive amygdaloid lesions would show similar alterations in a more molar response (escape) to several US levels. Such alterations, if demonstrated, might help to explain the inconsistent results obtained with rats.

\section{EXPERIMENT}

Method

Subjects were 11 male albino rats (Holtzman) weighing $300-314 \mathrm{~g}$ at the time of surgery.

Testing was carried out in a modified shuttle box consisting of two $12 \frac{1 / 2}{2} \times 11 \times 8$ in. plywood chambers connected by a $4 \frac{1}{4}$ $x 5$ in. door. The grid floor of each compartment was connected to a shock generator-grid scrambler (Grason-Stadler, E6070B), a Cramer $(1 / 100 \mathrm{sec})$ timer and a telegraph key. Depressing the telegraph key simultaneously started (while release stopped) the timer and shock generator. Grid shock was monitored with an ac milliameter.

All operations were performed under clean conditions with sodium pentobarbital anesthesia $(40 \mathrm{mg} / \mathrm{kg})$. Amygdaloid lesions $(\mathrm{N}=6)$ were produced by passing $2.0 \mathrm{~mA}$ anodal $\mathrm{dc}$ through the uninsulated tip of a stainless steel insect pin for $20 \mathrm{sec}$. Three Ss received control operations and the remaining Ss $(\mathrm{N}=2)$ were simply anesthetized.

After 28 days of recovery and adaptation to the testing apparatus, escape trials began. A trial started with the onset of intermittent shock and ended when $S$ escaped to the opposite chamber or when $60 \mathrm{sec}$ elapsed without escape. Ss received 10 trials per day throughout the experiment with the intertrial interval randomly varied between 15 and $75 \mathrm{sec}$. Ss were tested for 70 trials with a US level of $0.5 \mathrm{~mA}$, followed by 70 trials at $0.1 \mathrm{~mA}$, and finally 70 trials at $1.0 \mathrm{~mA}$

\section{Results}

Escape latencies for the three US levels are summarized in Fig. 1. At the 0.5-mA level, amygdalectomized Ss escaped reliably faster than control Ss $(F=14.11, \mathrm{df}=1 / 9, \mathrm{p}<.005)$. The performance of the two groups became more similar on later trials $(F=3.83, \mathrm{df}=6 / 54, \mathrm{p}<.005)$, however, and was indistinguishable by the last day $(t<1.0)$. Analysis of the first 10 training trials revealed a steady increase in escape latency for both groups $(\mathrm{F}=2.40, \mathrm{df}=9 / 81, \mathrm{p}<.05)$. Although the latencies of both groups was closely similar on Trial 1 $(t<1.0)$, the latencies of the amygdalectomized Ss increased less rapidly than those of the control $\mathrm{Ss}(\mathrm{F}=6.09, \mathrm{df}=1 / 9$, $p<.05)$. There was a marginal Treatment by Trials interaction $(F=1.90, \mathrm{df}=9 / 81, .05<\mathrm{p}<.10)$.

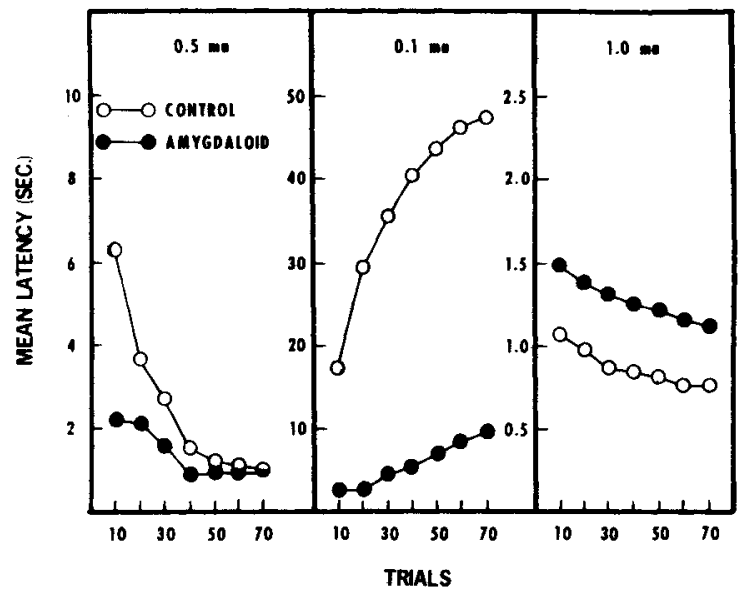

Fig. 1. Mean daily (10 trials) escape latencies for amygdaloid and control groups at each US level. (Note changes in ordinate scale.)

Reduction of the US level to $0.1 \mathrm{~mA}$ resulted in a steady increase in escape latency $(F=12.66, \mathrm{df}=6 / 54, \mathrm{p}<.001)$. As can be seen in the middle panel of Fig. 1, amygdaloid and control groups differed markedly in the rate at which their latencies increased $(F=5.66, \mathrm{df}=6 / 54, \mathrm{p}<.001)$ with the amygdaloid Ss escaping reliably faster than control Ss $(\mathrm{F}=16.31, \mathrm{df}=1 / 9, \mathrm{p}<.005)$.

Increase of the US to the $1.0-\mathrm{mA}$ level resulted in a sudden reduction in escape latency which continued to grow shorter throughout this phase $(F=20.00, \mathrm{df}=6 / 54, p<.001)$. Surprisingly, however, the amygdalectomized $\mathrm{Ss}$ now ran consistently slower than control animals $(F=7.65$. $\mathrm{df}=1 / 9$. $\mathrm{p}<.025$ ). Moreover, there was no suggestion of a Treatment by Days interaction $(F=0.25)$.

Finally, the mean initial (Trial Block 1) latencies for each US level were compared. This comparison is illustrated in Fig. 2. Although the latencies of both groups decreased as US intensity increased $(F=4.68, \mathrm{df}=2 / 18, \mathrm{p}<.025)$, the decrease was more pronounced in the control group $(F=8.39$, $\mathrm{df}=1 / 19, \mathrm{p}<.025)$

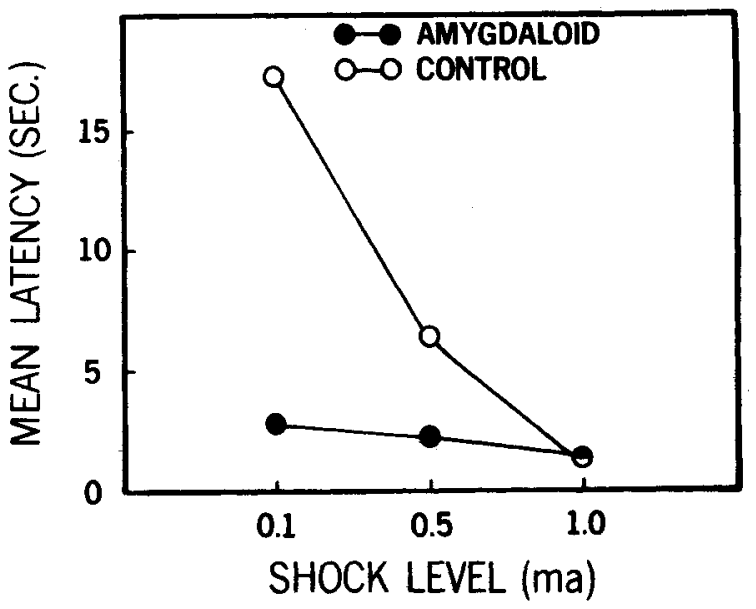

Fig. 2. Mean Day 1 (10 trials) escape latencies for amygdaloid and control groups at each USlevel. 
EXPERIMENT 2

One possible explanation for the longer latencies of amygdalectomized Ss at the $1.0-\mathrm{mA}$ level in Experiment 1 is that their performance resulted from the perseveration of responses established at previous $(0.5-$ and $0.1-\mathrm{mA})$ US levels. If this interpretation is correct, amygdalectomized Ss might be expected to escape at least as quickly as control Ss if the $1.0-\mathrm{mA}$ level were tested first. Experiment 2 was designed to test this possibility.

\section{Method}

Subjects were 26 male albino rats (Holtzman) weighing $309-325 \mathrm{~g}$ at the time of surgery. Fourteen Ss sustained amygdaloid lesions, six Ss received control operations, and the remaining six Ss were simply anesthetized.

\section{Apparatus and Procedures}

The apparatus and testing procedures were identical to those in Experiment 1 except that only one shock level $(1.0 \mathrm{~mA})$ was used.

\section{Results}

Mean escape latencies are presented in Fig. 3. It can be seen that the escape latencies of both groups became shorter on successive trial blocks $(F=26.39, \mathrm{df}=6 / 144, \mathrm{p}<.001)$ and that the amygdaloid group escaped consistently faster than the control group $(F=13.46, \mathrm{df}=1 / 24, p<.005)$. There was no reliable interaction between lesion conditions and trial blocks. Analysis of the first 10 trials once again revealed a steady increase in latency for both groups $(F=2.76$, df $=9 / 216$, $\mathrm{p}<.01)$. However, the group differences were marginal $(\mathrm{F}=3.81, \mathrm{df}=1 / 24, .05<\mathrm{p}<.10)$ and there was no suggestion of a Treatment by Trials interaction $(F=0.76)$.

\section{Histology}

All lesions included extensive bilateral damage to the amygdaloid complex (only the medial amygdaloid nucleus was frequently spared) and ventral pyriform cortex. Damage to the internal capsule and caudate-putamen was infrequent $(\mathrm{N}=4)$ and minor in the two experiments and produced no noticeable differences in performance. Two representative amygdaloid lesions are reconstructed in Fig. 4. The size and placement of amygdaloid lesions was quite comparable in both experiments.

\section{DISCUSSION}

The progressive increase in escape latency noted during the first 10 trials of both experiments indicates that the Ss rapidly developed a reluctance to enter a chamber where they had been previously shocked. Thus, the shorter latencies of the amygdalectomized Ss seem to reflect, in part at least, a failure

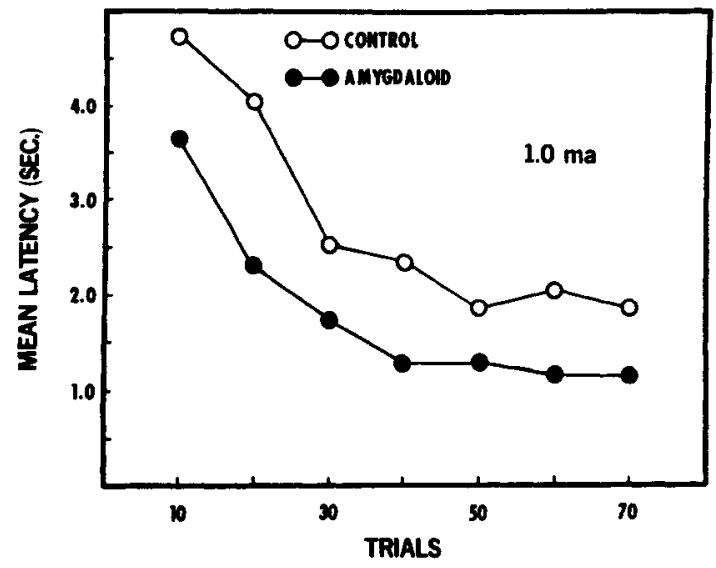

Fig. 3. Mean daily escape latencies for amygdaloid and control groups.
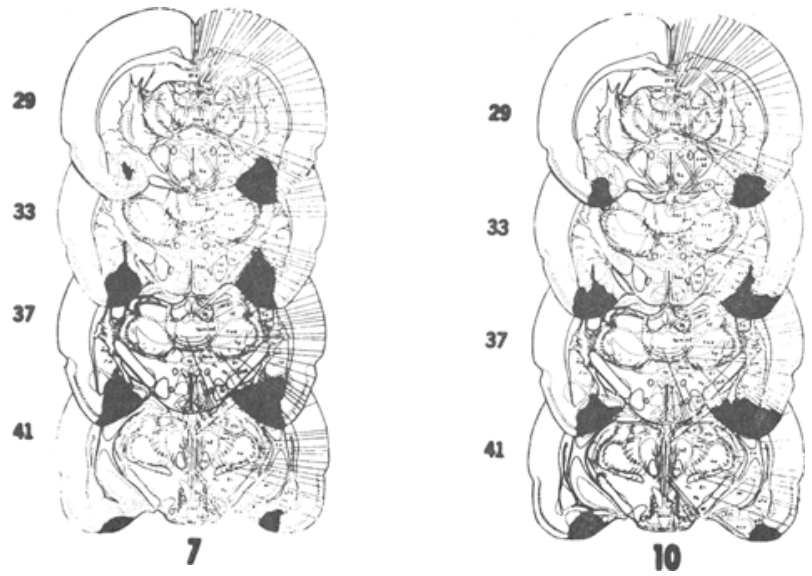

Fig. 4. Reconstruction of two representative amygdaloid lesions projected on plates from König and Klippel (1963).

to inhibit approach responses to the opposite compartment (passive avoidance). In this connection it is interesting to note that the experiments of Robinson (1963) and McNew \& Thompson (1966), which demonstrated amygdaloid deficits in active avoidance, employed apparatus in which the "danger" and "safe" compartments were dissimilar. This dissimilarity presumably reduced or eliminated any passive avoidance component in the active avoidance task. Thus, the previous failures to demonstrate amygdaloid active avoidance deficits may have resulted from the inadvertant inclusion of a passive avoidance component in the task. This possibility is being investigated.

Experiment 1 also indicates that the escape response of amygdalectomized Ss, once established, is very insensitive to changes in US intensity. This finding is consistent with the decreased responsiveness to food deprivation and changes in magnitude of reward observed by Schwartzbaum $(1960,1961)$ in amygdalectomized monkeys.

\section{REFERENCES}

BAGSHAW, M. H., \& PRIBRAM, J. D. Effect of amygdalectomy on stimulus threshold of the monkey. Experimental Neurology, 1968, 20, 197-202.

DICARA, L. V. Effect of amygdaloid lesions on avoidance learning in the rat. Psy chonomic Science, 1966, 4, 279-280.

KEMBLE, E. D., \& TAPP, J. T. Passive and active avoidance performance following small amygdaloid lesions in rats. Physiology \& Behavior, 1968, 3, 713-718.

KÖNIG, J. F. R., \& KLIPPEL, R. A. The rat brain. Baltimore: Williams \& Wilkins, 1963.

McNEW, J. J., \& THOMPSON, R. Role of the limbic system in active and passive avoidance conditioning in the rat. Journal of Comparative \& Phy siological Psychology, 1966, 61, 173-180.

ROBINSON, E. Effect of amygdalectomy on fear-motivated behavior in rats. Joumal of Comparative \& Physiological Psychology, 1963, 56, 814-820.

SCHWARTZBAUM, J. S. Changes in reinforcing properties of stimuli following ablation of the amygdaloid complex in monkeys. Joumal of Comparative \& Physiological Psychology, 1960, 53, 388-395.

SCHWARTZBAUM, J. S. Some characteristics of "amygdaloid hyperphagia" in monkeys. American Journal of Psychology, 1961, 74, 252-259.

NOTE

1. This research was supported by a grant-in-aid of research from the Graduate School of the University of Minnesota. 